\title{
Armpje drukken: Aanval de beste verdediging?
}

\author{
drs. L. Brouwers ${ }^{1}$, prof. dr. M.H.J. Verhofstad², drs. D.I. Vos ${ }^{1}$ \\ Afdeling Chirurgie, Amphia ziekenhuis Breda ${ }^{1}$ en Erasmus Medisch Centrum \\ Rotterdam ${ }^{2}$
}

\section{Inleiding}

Humerusschachtfracturen kunnen veroorzaakt worden door een direct trauma, een val op de gebogen elleboog of hand met uitgestrekte arm of door een plotselinge rotatiebeweging. Een direct trauma resulteert meestal in een dwarse fractuur. Een plotselinge rotatiebeweging resulteert vaak in een spiraalfractuur in het bijzonder in het distale deel van de humerus.

'Armpje drukken' of 'arm worstelen' is een bezigheid die door jong volwassen mannen veelvuldig op recreatief, maar ook op competitief niveau wordt beoefend. Toch is deze activiteit minder onschuldig dan het in eerste instantie lijkt.

In deze klinische les presenteren wij 3 patiënten met een distale humerusschachtfractuur ten gevolge van een 'wedstrijdje armpje drukken'. Biomechanische en tactische aspecten van dit letsel worden besproken: 'Is aanval de beste verdediging?' 


\section{Casus}

Patiënt A, een 22-jarige rechtshandige man, hoorde en voelde een plotselinge 'knap' in zijn linker bovenarm tijdens het armworstelen in een café, gevolgd door hevige pijn en actieve bewegingsbeperking. Hij presenteerde zich op de afdeling Spoedeisende Hulp (SEH) met asdrukpijn en tintelingen in zijn handpalm, vingertoppen en duim. De motoriek van de pols, hand en vingers was intact. Navraag leerde dat hij vier keer per week naar de sportschool ging en voedingssupplementen tot zich nam. Op het moment van trauma verkeerde de wedstrijd in evenwicht.

De gemaakte röntgenfoto liet een gedisloceerde, distale spiraalfractuur van de humerus zien (AO classificatie $12 \mathrm{~A} 1$, figuur I). Gezien de mate van dislocatie werd besloten tot open repositie en interne fixatie (ORIF) met een plaatosteosynthese. Postoperatief waren de gevoelsstoornissen in de linker hand verdwenen. Twee maanden na het ongeval was de patiënt vrijwel klachtenvrij en was er een vorderende consolidatie (figuur II).

Patiënt B, een 22-jarige man voelde tijdens een recreatieve wedstrijd armworstelen in een discotheek, plotseling een scherpe pijn in zijn dominante rechter arm. Bij anamnese bleek dat hij op het moment van het ontstaan van de pijn aan het verliezen was en met een laatste krachtsinspanning alsnog wilde winnen. Hij bezocht zes keer per week een sportschool en gebruikte voedingssupplementen. Bij presentatie op de SEH zagen we een forse zwelling proximaal van de rechter elleboog. De motoriek en sensibiliteit waren intact. Op de röntgenfoto werd een spiraalfractuur van de distale humerus (AO classificatie 12 B3) gezien zonder dislocatie. Er werd gekozen voor een niet-operatieve behandeling met een Sarmiento-brace en orale pijnstilling. De fractuur genas restloos en na drie maanden kon hij zijn fitness activiteiten hervatten.

Patiënt C, een 21-jarige rechtshandige man, voelde tijdens een recreatief wedstrijdje armworstelen een 'knap' in zijn linker arm, hierbij sloeg zijn arm achterover tegen de tafel. Bij lichamelijk onderzoek werd een forse zwelling waargenomen in de linker bovenarm en beweging van de elleboog was niet meer mogelijk. Dorsaal flexie van de hand en de sensibiliteit aan de dorsale zijde van de onderarm, pols en hand waren afwezig, passend bij een motorisch en sensorisch functieverlies ten gevolge 
van neuropraxia van de nervus radialis (zgn. 'dropping hand'). Bij röntgendiagnostiek bleek er een spiraalfractuur van de distale humerus (AO classificatie 12 B1) met een anatomische goede stand. Er werd besloten tot niet-operatieve behandeling met een Sarmiento brace. Na 6 weken werd gestart met fysiotherapie en na 3 maanden was de fractuur radiologisch geconsolideerd in 15 graden varus, bij een verder volledig normale actieve range of motion (ROM). De neuropraxie van de nervus radialis verdween geleidelijk; de afwezige extensie van de hand werd gedurende de follow up niet meer waargenomen en de gevoelsstoornissen verdwenen geleidelijk.

\section{Beschouwing}

Armworstelen is een van de oudste krachtsporten uit de geschiedenis. Het 'moderne' armworstelen stamt af van het 'Indian wrestling' dat in de 19e eeuw werd beoefend door kolonisten in Amerika. Tegenwoordig organiseert de World Arm Wrestling Federation (WAF), waarbij 101 landen zijn aangesloten, jaarlijks een wereldkampioenschap. Armworstelaars in Nederland zijn verenigd bij de Nederlandse Armworstel Bond (NLAB). Armworstelen is in Nederland een kleine sport, maar wordt veelvuldig op recreatief niveau beoefend door jong en oud, man en vrouw. Het doel van de wedstrijd is met de eigen hand, de hand van de tegenstander met de dorsale zijde tegen de tafel te drukken, terwijl de elleboog van de wedstrijdarm op de tafel blijft steunen.

'Armpje drukken' is echter een minder onschuldige bezigheid dan het lijkt en kan resulteren in een, meestal distale, humerusschachtfractuur met of zonder begeleidend neurovasculair letsel (oa. Brazilië, Duitsland, Hong Kong, Israël, Nieuw Zeeland, USA en Zweden). Het is een typische "mannensport", vrouwen worden slechts in $10 \%$ van de casuïstiek beschreven. Humerusschachtfracturen ten gevolge van het armworstelen kunnen op elke leeftijd ontstaan (1). In de literatuur worden verschillende gespierde armworstelaars beschreven, maar ook patiënten met een 'normaal' postuur hadden humerusschachtfracturen. Het gebruik van de (niet)-dominante arm laat geen duidelijke verschillen zien(1). 
Humerusschachtfracturen worden over het algemeen veroorzaakt door een direct trauma tegen de bovenarm, een val op een gebogen elleboog of hand met uitgestrekte arm of door een plotselinge rotatiebeweging, zoals bij speerwerpen, roeien, granaatwerpen en honkbalwerpen $(2,3)$. Een direct trauma resulteert meestal in een dwarse fractuur, een rotatiebeweging in een spiraalfractuur. Deze spiraalfractuur bevindt zich meestal in het distale gedeelte van de humerus (4). De incidentie is laag incidentie en betreft $1-2 \%$ van alle fracturen. De kans op deze fractuur neemt toe vanaf na het vijftigste levensjaar (5).

De humerus vormt samen met de scapula het glenohumerale gewricht. Het rotatoren manchet (rotator cuff), bestaande uit de $\mathrm{m}$. supraspinatus, $\mathrm{m}$. infraspinatus, $\mathrm{m}$. teres minor en de $\mathrm{m}$. subscapularis, houdt het glenohumerale gewricht op zijn plaats. Hiermee komen alle bewegingen van de schouder tot stand. (tabel I). De armworstel beweging komt primair tot stand door een gecombineerde endorotatie van de bovenarm, pronatie van de onderarm en palmair flexie van de pols en secundair door flexie van de elleboog. Onderzoek van Oliveira Silva et al. en Kruczynski et al. Laat zien dat de $\mathrm{m}$. deltoideus, de $\mathrm{m}$. biceps brachii, $\mathrm{m}$. brachialis (flexie elleboog), de $\mathrm{m}$. subscapularis, $m$. pectoralis major (endorotatie) en de $m$. flexor carpi ulnaris (volaire flexie pols) maximale contractie ondergaan tijdens de wedstrijd $(4,6)$.

De meest gangbare theorie over het oplopen van een distale humerusschachtfractuur tijdens een armworstel wedstrijd werd voor het eerst beschreven door Brismar \& Spangen (7). Aangenomen wordt dat bij exorotatie van de humerus, tijdens een aanval van een van beide spelers, de endorotatoren in plaats van concentrisch, excentrisch contraheren en in een stress toestand raken. Deze plotselinge contractieverandering leidt, in combinatie met axiale compressie van de humerus en verschuiving van het lichaamsgewicht, tot rotatie van de distale humerus en de mogelijke spiraal fractuur (1). Uit onderzoek van Kruzynski et al. blijkt dat het distale een derde deel van de humerus het meest kwetsbaar is voor dergelijke roterende krachten en het snelst fractureert (4).

worden de armworstel beweging van één van beide spelers blootgesteld aan extreme krachten: exorotatie van de humerus, extensie van de elleboog, supinatie van de onderarm en dorsale flexie van de pols. 
De behandeling kan bestaan uit immobilisatie met een gipsverband of brace of operatief met een plaat of intramedullaire pen osteosynthese.

De fase waarin de wedstrijd zich bevond is uitvoerig beschreven in verschillende case-reports. Hierbij werd onderscheid gemaakt tussen een gelijkopgaande wedstrijd, of een wedstrijd waarin de patiënt aan de winnende of verliezende hand was. Opvallend is dat de fracturen in elke fase van de wedstrijd lijken voor te komen.(1) Echter ontstond de fractuur altijd op het moment dat een van de deelnemers door een plotselinge uiterste krachtsinspanning (excentrische contractie van de endorotatoren en verschuiving van het lichaamsgewicht) de winst probeerde te forceren.

Naast humerusschacht fracturen bij volwassenen worden mediale epicondyl fracturen bij adolescenten beschreven. Aangenomen wordt dat vanwege het immature skelet de distale groeischijf van de humerus de zwakke plek is. Sterke contractie van de polsflexoren en pronatoren van de onderarm leidt tot grote krachten op de origo ter plaatse van de mediale epicondyl en de uiteindelijke fractuur.

Een subscapularis- en proximale biceps peesruptuur, tuberculum minus fractuur, anterieure dislocatie van de elleboog en een olecranonfractuur zijn andere blessures die ten gevolge van armworstelen beschreven zijn.(8-14) Een bijzondere vorm van humerusschacht fracturen wordt gezien bij een arm-worstelmachine, waarbij men een wedstrijd armworstelt tegen een computer.(15)

Patiënten presenteren zich op de SEH met pijn aan de bovenarm en een plotseling verlies van functie van de arm waarbij verteld wordt dat de aangedane arm plotseling doorsloeg na het horen van een "knap".. Radiologische opnames tonen een spiraalfractuur rondom het distale $1 / 3$ van de humerus met of zonder een vlinderfragment. De behandeling bestaat uit immobilisatie met een gipsverband of brace bij distale humerus fracturen die weinig tot niet gedisloceerd zijn. Bij dislocatie van de fractuur is plaatschroef osteosynthese of intramedullaire pen geïndiceerd.(7, 16-18) 
Nervus radialis letsel is de enige complicatie die in de literatuur beschreven wordt. De incidentie loopt in de literatuur uiteen van $10 \%$ tot $23 \%$. Het letsel herstelt uit zichzelf en behoeft geen chirurgische behandeling. $(1,19,20)$

Tips en tricks toevoegen

\section{Conclusie}

Armworstelen is een populaire sport die veelvuldig recreatief beoefend wordt. Het is echter ook een sport welke zonder het gebruik van de juiste technieken en training zeer blessuregevoelig kan zijn. Distale humerus fracturen kunnen voorkomen wanneer een deelnemer met een plotselinge kracht inspanning de winst probeert te forceren. Geadviseerd wordt een tegenstander te zoeken van dezelfde omvang en formaat.

Nader onderzoek dient uitgevoerd te worden naar de lengte van de onderarm in vergelijking met de tegenstander. Gezien het feit dat er sprake is van een grotere hefboom, betekent dit dan ook dat er groter voordeel is? 


\section{Literatuur:}

1. Ogawa K, Ui M. Humeral shaft fracture sustained during arm wrestling: report on 30 cases and review of the literature. J Trauma. [Review]. 1997 Feb;42(2):243-6.

2. Branch T, Partin C, Chamberland P, Emeterio E, Sabetelle M. Spontaneous fractures of the humerus during pitching. A series of 12 cases. Am J Sports Med. 1992 Jul-Aug;20(4):468-70.

3. Ogawa K, Yoshida A. Throwing fracture of the humeral shaft. An analysis of 90 patients. Am J Sports Med. 1998 Mar-Apr;26(2):242-6.

4. Kruczynski J, Jaszczur Nowicki J, Topolinski T, Srokowski G, Manko G, Chantsoulis M, et al. Radiological and biomechanical analysis of humeral fractures occurring during arm wrestling. Med Sci Monit. [Research Support, Non-U.S. Gov't]. 2012 May;18(5):CR303-7.

5. Ekholm R, Adami J, Tidermark J, Hansson K, Tornkvist H, Ponzer S. Fractures of the shaft of the humerus. An epidemiological study of 401 fractures. J Bone Joint Surg Br. 2006 Nov;88(11):146973.

6. Silva DC, Silva Z, Sousa Gda C, Silva LF, Marques Kdo V, Soares AB, et al. Electromyographic evaluation of upper limb muscles involved in armwrestling sport simulation during dynamic and static conditions. J Electromyogr Kinesiol. [Research Support, Non-U.S. Gov't]. 2009 Dec;19(6):e44857.

7. Brismar B, Spangen L. Fracture of the humerus from arm wrestling. Acta Orthop Scand. [Case Reports]. 1975 Sep;46(4):707-8.

8. Biondi J, Bear TF. Isolated rupture of the subscapularis tendon in an arm wrestler. Orthopedics. [Case Reports]. 1988 Apr;11(4):647-9.

9. Lokiec F, Velkes S, Engel J. Avulsion of the medial epicondyle of the humerus in arm wrestlers: a report of five cases and a review of the literature. Injury. [Case Reports]. 1991 Jan;22(1):69-70.

10. Nyska M, Peiser J, Lukiec F, Katz T, Liberman N. Avulsion fracture of the medial epicondyle caused by arm wrestling. Am J Sports Med. [Case Reports]. 1992 May-Jun;20(3):347-50.

11. Pasquina PF, O'Connor FG. Olecranon fracture sustained in arm wrestling. Phys Sportsmed. 1999 Apr;27(4):81-7.

12. Pratt DA, Tennent TD. Proximal biceps rupture: management of an unusual injury in an arm wrestler. Br J Sports Med. [Case Reports]. 2007 Jul;41(7):459.

13. Ross GJ, Love MB. Isolated avulsion fracture of the lesser tuberosity of the humerus: report of two cases. Radiology. [Case Reports]. 1989 Sep;172(3):833-4.

14. Torchia ME, DiGiovine NM. Anterior dislocation of the elbow in an arm wrestler. J Shoulder Elbow Surg. [Case Reports]. 1998 Sep-Oct;7(5):539-41.

15. Helm RH, Stuart P. Fracture of humerus during use of an arm wrestling machine. Br Med J (Clin Res Ed). [Case Reports]. 1986 Dec 20-27;293(6562):1644.

16. de Barros JW, Oliveira DJ. Fractures of the humerus in arm wrestling. Int Orthop. [Case Reports]. 1995;19(6):390-1.

17. Heilbronner DM, Manoli A, 2nd, Morawa LG. Fractures of the humerus in arm wrestlers. Clin Orthop Relat Res. [Case Reports]. 1980 Jun(149):169-71.

18. Saab M. Arm wrestler's fracture. Eur J Emerg Med. [Case Reports]. 1999 Dec;6(4):407-8.

19. Chiu KY, Pun WK, Chow SP. Humeral shaft fracture and arm-wrestling. J R Coll Surg Edinb. [Case Reports]. 1990 Aug;35(4):264-5.

20. Low BY, Lim J. Fracture of humerus during armwrestling: report of 5 cases. Singapore Med J. [Case Reports]. 1991 Feb;32(1):47-9. 
Bijlagen:

Figuur I

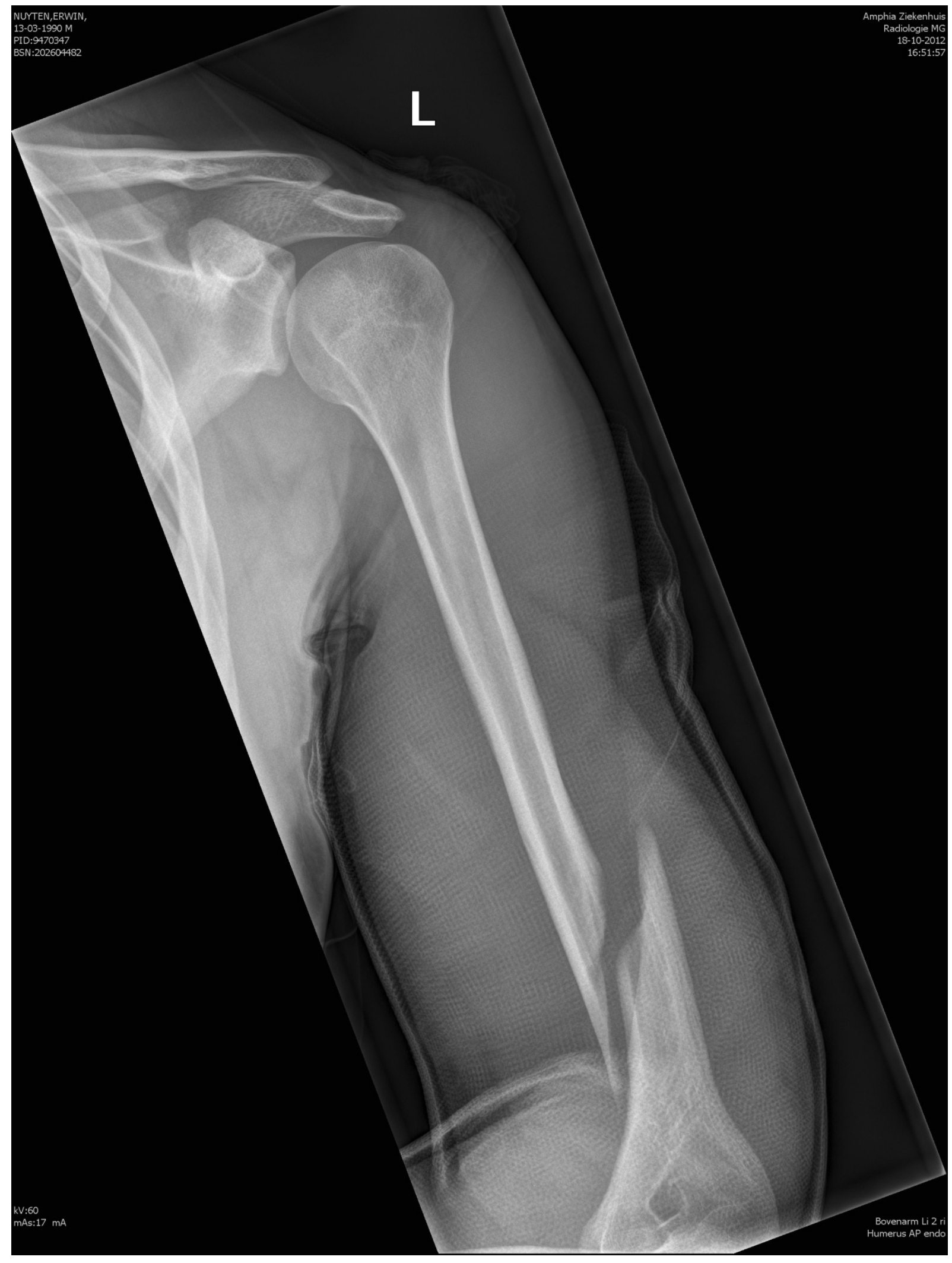


Figuur II

2 maanden na het ongeval

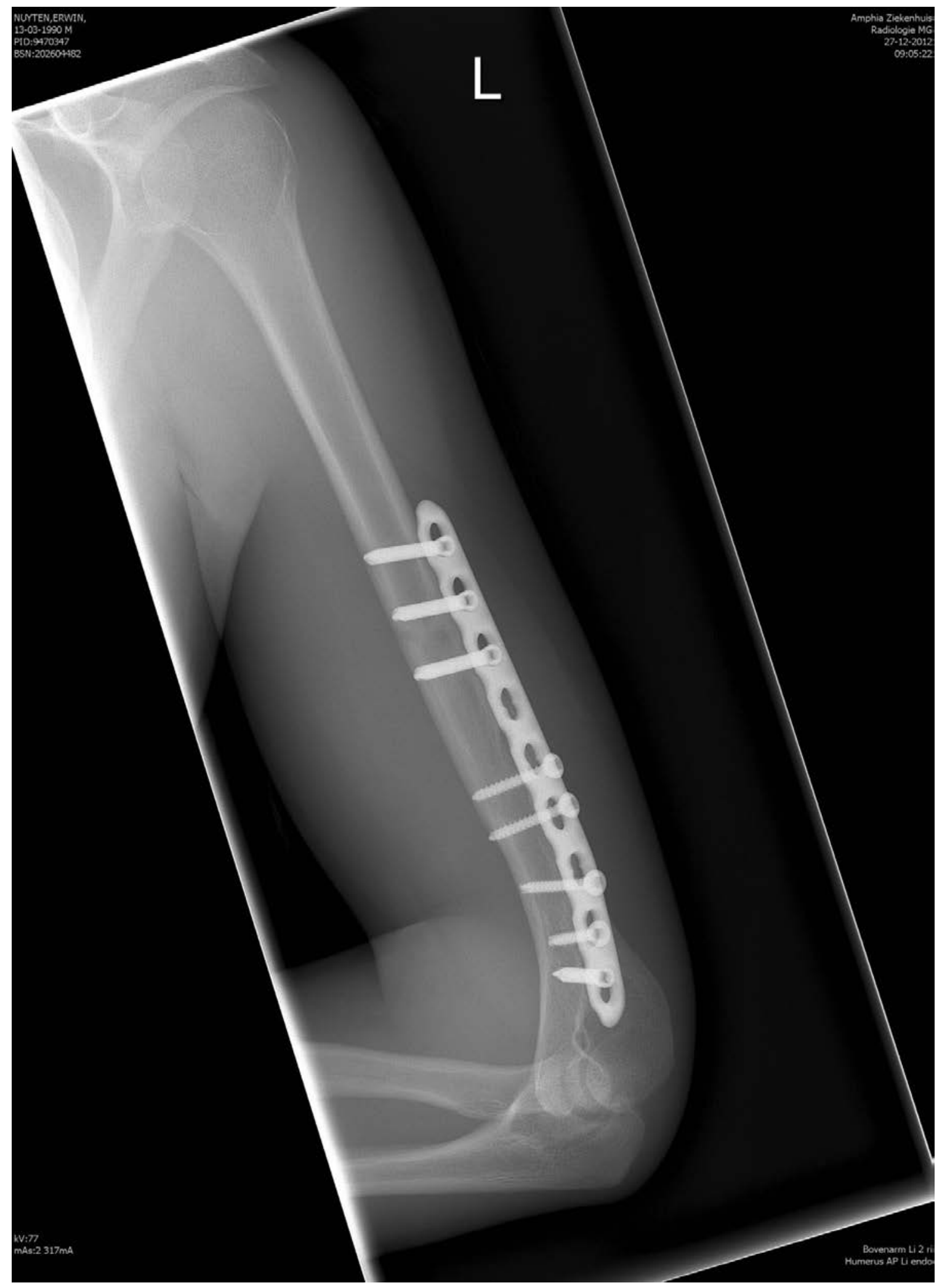


Tabel I

\begin{tabular}{|c|c|c|c|c|c|c|c|}
\hline Anteflexie & $\begin{array}{l}\text { Retrofl } \\
\text { exie }\end{array}$ & Abductie & $\begin{array}{l}\text { Adduc } \\
\text { tie }\end{array}$ & $\begin{array}{l}\text { Exorotat } \\
\text { ie }\end{array}$ & $\begin{array}{l}\text { Endorota } \\
\text { tie }\end{array}$ & $\begin{array}{l}\text { Exten } \\
\text { sie } \\
\text { ellebo } \\
\text { og }\end{array}$ & $\begin{array}{l}\text { Flexie } \\
\text { elleboog }\end{array}$ \\
\hline $\begin{array}{l}\text { Deltoideus } \\
\text { Pectoralis } \\
\text { maj } \\
\text { Coracobra } \\
\text { chialis }\end{array}$ & $\begin{array}{l}\text { Deltoid } \\
\text { eus } \\
\text { Teres } \\
\text { major } \\
\text { Lattisi } \\
\text { mus } \\
\text { dorsi }\end{array}$ & $\begin{array}{l}\text { Deltoideu } \\
\text { s } \\
\text { Supraspi } \\
\text { natus }\end{array}$ & $\begin{array}{l}\text { Pector } \\
\text { alis } \\
\text { maj } \\
\text { Lattisi } \\
\text { mus } \\
\text { dorsi }\end{array}$ & $\begin{array}{l}\text { Infraspin } \\
\text { atus } \\
\text { Teres } \\
\text { minor }\end{array}$ & $\begin{array}{l}\text { Subscap } \\
\text { ularis } \\
\text { Pectorali } \\
\text { s maj } \\
\text { Infraspin } \\
\text { atus } \\
\text { Teres } \\
\text { major }\end{array}$ & $\begin{array}{l}\text { Tricep } \\
\text { s } \\
\text { brachii } \\
\text { Ancon } \\
\text { eus }\end{array}$ & $\begin{array}{l}\text { Biceps } \\
\text { brachii } \\
\text { Brachialis } \\
\text { Brachiora } \\
\text { dialis } \\
\text { Extensor } \\
\text { carpi } \\
\text { radialis } \\
\text { longus \& } \\
\text { brevis }\end{array}$ \\
\hline
\end{tabular}

